\title{
O ENGENHO BOM FIM E O LUGAR SOCIAL DA MULHER NEGRA NO PÓS-ABOLIÇÃO (AREIA-PB, 1890-1920)
}

\author{
Geilza da Silva Santos ${ }^{1}$
}

\begin{abstract}
Resumo
O presente artigo tem por finalidade central abordar sobre o lugar social das mulheres negras no munícipio de Areia-PB no pós-abolição, precisamente no local em que viria a se constituir a Comunidade Negra do Bonfim. Apesar da posse oficial das terras pelos quilombolas ter ocorrido apenas em 2011, já estão naquela região há mais de 100 anos, pois foi no período compreendido entre 1913 e 1920 que os primeiros moradores chegaram à propriedade Engenho Bonfim. Dessa forma, em busca de respostas à problemática a que nos propomos, utilizaremos os censos do munícipio de Areia de 1872 a 1920, que juntamente com uma historiografia local, o relatório antropológico da comunidade e os relatos orais de algumas moradoras, nos nortearão sobre a vida das mulheres negras nesse munícipio no pós-abolição.
\end{abstract}

Palavras chaves: Invisibilidade; Mulheres Negras; Pós-abolição.

\begin{abstract}
The present work has as a central aim to approach about the social place of black women in the city of Areia-PB on Post-Abolition, accurately at the place where the Black Community of Bonfim would be formed. Although the official possession of lands by quilombolas had occurred only 2011, they had been in this region for over 100 years, the first residents had arrived at Engenho Bom Fim property since 1913-1920. Thus, in search of answers about the problem that we proposed, we will use the Areia's censuses from 1872 to 1920 , together with a local historiography, anthropological report of the Community and women's oral report who residents in this local. All of this will guide us about the black women's life on Post-Abolition at this city.
\end{abstract}

Keywords: Invisibility; Black Women; Post-Abolition.

\footnotetext{
${ }^{1}$ Doutoranda em História pela Universidade Federal Rural de Pernambuco e bolsista da Coordenação de Aperfeiçoamento de Pessoal de Nível Superior (CAPES).
} 


\section{Introdução}

O "negro africano" fora tirado de suas terras, dos seus hábitos, das suas crenças, dos seus deuses e trazido para as Américas. Tendo sido imposto a eles novos costumes, novas práticas, novas crenças e a ideia do "negro bárbaro", inventada na Europa, na frenética busca de se impor a outras culturas, de projetar a superioridade branca/ocidental/cristã. Isso resultou na visão do negro como sujeito inferior, bárbaro, sem cultura, sem inteligência, ou seja, em sua "coisificação". Embora de origens étnicas diferenciadas, os negros foram transformados de acordo com uma visão eurocêntrica, em africanos, como se fossem um grupo homogêneo, não levando em consideração a multiplicidade de línguas, religiões e culturas. Chegando ao Brasil, se depararam com um ambiente de trabalho compulsório, de exploração e produção de riquezas.

Foram tirados de suas terras para serem escravizados sob a justificativa da classe dominante de que estavam fazendo-os um favor, pois estavam tirando-os da ignorância em que viviam, através principalmente, da conversão ao cristianismo. Tendo o apoio da religião, a escravidão não era questionada, sendo desígnio de Deus, como nos aponta Emília Viotti: “Acreditava-se que era a vontade de Deus que alguns nascessem nobres, outros, vilões, uns, ricos, outros, pobres, uns, livres, outros escravos. De acordo com essa teoria, não cabia aos homens modificar a ordem social" "2. E assim, os negros eram vistos como inferiores e deveriam viver como escravizados. Esse discurso era utilizado para legitimar a aceitação do "seu lugar".

Mesmo depois da abolição, a situação não melhorou. Portanto, não seria o fim da escravidão, sancionada com a lei de 13 de maio de 1888, que iria trazer melhores condições de vida ao negro. A liberdade não foi sinônimo de igualdade e cada vez mais essa população foi sendo colocada à margem da sociedade. A "liberdade" não resultou em mais igualdade social e até hoje os descendentes dos negros escravizados carregam consigo o peso de uma sociedade excludente e que os inferioriza.

Sabe-se que a formação econômica do país se deu pela força de trabalho negra, a primeira tendo sido conduzida de forma desigual para com esta população, que responde e sofre com o relativo desemprego e que atualmente, em vários espaços, ocupa postos considerados “inferiores". Com a abolição houve uma grande dificuldade para a inserção dos homens e mulheres, ex-escravos, na sociedade, com grandes desvantagens

\footnotetext{
${ }^{2}$ COSTA, Emília Viotti da. A abolição. 9. ed. São Paulo: Editora UNESP, 2010, p. 13.
} 
principalmente para as mulheres negras. Aqueles que sonhavam com a mobilidade social se depararam com o preconceito racial e assim, foram e são excluídos.

O mercado de trabalho foi um exemplo da triste realidade dos negros no Brasil. Mesmo com a modernização, com a expansão industrial e com o dinamismo maior de atividades produtivas, é notória uma ainda continuidade das diferenças de papéis nos grupos da sociedade. Como salienta a ativista negra Theresa Santos: "no país da 'democracia racial', saímos da condição de escravos para a semiescravidão"3 fator racial enquanto marcador das diferenças, relegado às pessoas negras o lugar mais baixo da hierarquia.

Desse modo, nosso artigo é direcionado no sentido de perceber "o lugar" que a mulher negra ocupou no pós-abolição, analisando através dos censos, da historiografia local e do relatório antropológico ${ }^{4}$ da comunidade, como foram ocupando cargos e funções que lhes foram relegados desde a escravidão, sem perspectivas de mobilidade em uma sociedade hierarquizada. Bem como a utilização de entrevistas com algumas moradoras da comunidade, utilizando-se de fontes orais ${ }^{5}$ para o constructo do lugar social que as mulheres negras vinham ocupando nessa região. Nesta perspectiva, a memória se torna central para analisar a construção sobre as mulheres negras que constituíram o grupo. Desse modo, partimos do pressuposto apontado pelo sociólogo Michel Pollak de que a memória é seletiva e sofre alterações em função do momento em que é articulada, em que está sendo expressa, além de que existem nas lembranças de uns e de outros, zonas de sombra, silêncios e "não-ditos". A memória seria, portanto, um fenômeno construído, resultante de um trabalho de organização. Segundo Pollak: "o que a memória individual grava, recalca, exclui, relembra, é evidentemente o resultado de um verdadeiro trabalho de organização" 6 .

\footnotetext{
3 SANTOS, Thereza. Malunga Thereza Santos: a história de vida de uma guerreira. São Carlos: EDUFSCAR, 2008, p. 134.

${ }^{4}$ O Relatório Antropológico de Reconhecimento e Delimitação do Território (RTID) traz informações cartográficas, fundiárias, agronômicas, ecológicas, geográficas, socioeconômicas, históricas e antropológicas das Comunidades Negras que buscam reconhecimento como quilombolas. Cf.: BRASIL. Relatório Antropológico de Reconhecimento e Delimitação do Território da Comunidade Negra Senhor do Bonfim. Instituto Nacional de Colonização e Reforma Agrária - INCRA, Superintendência Regional Paraíba, João Pessoa, n. 18, 2007.

5 Alessando Portelli concebe a história oral como arte da escuta, apontando essa expressão como uma abreviação para o uso das fontes orais na História e acrescenta: "as narrativas orais e os testemunhos que constituem a história oral não são mais do que uma ferramentas adicional na panóplia de fontes do historiador - e assim, estão sujeitas ao mesmo escrutínio crítico que todas as outras fontes, a fim de verificar sua confiabilidade e usabilidade. Cf.: PORTELLI, Alessandro. História oral como arte da escuta. São Paulo: Letra e Voz, 2016, p. 09.

${ }^{6}$ POLLAK, Michael. Memória e Identidade Social. Revista Estudos Históricos, Rio de Janeiro, v. 05, n. 20, 1992, p. 203-204.
} 
A priori, abordaremos um pouco sobre uma historiografia inicial acerca dos estudos sobre as mulheres. Além disso, destacaremos a luta de algumas ativistas que buscaram trazer ao cerne da questão o debate sobre as mulheres negras, enfatizando a importância de se falar sobre esse assunto, buscando uma visibilidade acerca da inserção da discussão na sociedade brasileira. Por fim, traremos uma discussão sobre a mulher negra no pós-abolição no munícipio de Areia-PB ${ }^{7}$.

\title{
Reflexões acerca dos estudos sobre as "mulheres"
}

A história das mulheres vem ganhando maior visibilidade na contemporaneidade em contraponto a uma historiografia majoritariamente masculina. O silêncio na historiografia sobre as mulheres resulta da não valorização do seu papel, da noção arraigada de uma superioridade masculina. No entanto, os movimentos feministas e pesquisas acadêmicas tentam romper cada vez mais com esses discursos, contrapondo-se a uma historiografia excludente, tendo por contribuição as historiadoras feministas e o descrédito das correntes historiográficas polarizadas para um sujeito universal. Nas palavras de Rachel Soihet e Joana Maria Pedro ${ }^{8}$ :

\begin{abstract}
A história das mulheres - com suas compilações de dados sobre as mulheres no passado, com suas afirmações de que as periodizações tradicionais não funcionavam quando as mulheres eram levadas em conta, com sua evidência de que as mulheres influenciavam os acontecimentos e tomavam parte na vida pública, com sua insistência de que a vida privada tinha uma dimensão pública - implicava a negação de que o sujeito da história constituía-se numa figura universal ${ }^{9}$.
\end{abstract}

A fertilidade de estudos acerca dessa temática nos dias atuais contrasta com a trajetória difícil que a categoria de análise "gênero" enfrentou no campo historiográfico. Nas ciências humanas, a disciplina História é certamente a que mais tardiamente apropriou-se dessa categoria, assim como da própria inclusão das mulheres como

\footnotetext{
${ }^{7} \mathrm{O}$ município de Areia está situado na microrregião do Brejo paraibano, no alto do planalto da Borborema, possui uma área de $269.596 \mathrm{~km}^{2}$, com 23.829 habitantes e fica a $130 \mathrm{~km}$ da capital João Pessoa. O clima é o tropical quente e úmido, pluviosidade situa-se em torno de $1500 \mathrm{~mm}$ bem distribuídos. A geologia está sob predomínio da unidade morfoestrutural Planalto da Borborema, com capeamentos da Formação Serra dos Martins; o relevo apresenta configurações morros de topos planos, vales, várzeas áreas dissecadas à barlavento. Foi reconhecida como Patrimônio Histórico Nacional em 11 de agosto de 2005, pelo Conselho Consultivo do IPHAN e homologado pelo Ministério da Cultura, através da portaria n ${ }^{\circ} 073$, de 29 de agosto de 2006 .

${ }^{8}$ Nesse artigo as autoras buscam apresentar a trajetória do campo historiográfico da "história das mulheres e das relações de gênero". Cf.: SOIHET, Raquel; PEDRO, Joana Maria. A emergência da pesquisa da história das mulheres e das relações de gênero. Revista Brasileira de História, São Paulo, v. 27, n. 54, 2007. ${ }^{9}$ SOIHET, Raquel; PEDRO, Joana Maria. A emergência da pesquisa da história das mulheres e das relações de gênero, p. 286.
} 
categoria analítica na pesquisa histórica ${ }^{10}$. Esse fato se deu, principalmente, pela ideia do "homem", leia-se o homem branco e ocidental, como o único sujeito histórico, a partir da errônea perspectiva de que se estava falando dos homens, as mulheres estariam contempladas.

As transformações na historiografia, aliadas à explosão do feminismo, tiveram "papel chave" no processo em que as mulheres são percebidas enquanto "objeto" e sujeito da história e assim, emergindo a história das mulheres. No entanto, é preciso salientar que as mudanças na historiografia a partir da Escola dos Annales, por exemplo, não implementaram a "história das mulheres", mas ao ampliar as fontes e sujeitos da história contribuíram para que esse campo tivesse possibilidades de emergir. Joana Maria Pedro salienta que a Escola dos Annales seria uma "confraria masculina", em que na maioria das vezes utilizava o trabalho gratuito das mulheres, "em geral suas esposas, as quais eram encontradas como estudantes, nos bancos das faculdades. Poucos historiadores fazem referência a esse trabalho gratuito, nos prólogos de seus livros ${ }^{11}$ ".

Algumas autoras trouxeram contribuições importantes para as pesquisas sobre a "história das mulheres". As obras de Michelle Perrot, Joan Scott, Margareth Rago, entre tantas outras, trazendo a temática das mulheres na história, pensando-as enquanto sujeitos históricos. Michelle Perrot ${ }^{12}$ contempla vários olhares sobre as mulheres, colocando-as como protagonistas. Traçando uma discussão historiográfica sobre as diversas maneiras de se escrever sobre as mulheres, sendo sujeitos dos seus próprios relatos, modificando assim a maneira de se escrever a história das mulheres. Joan $\operatorname{Scoot}^{13}$ aponta a multiplicidade dos desdobramentos que engloba as mulheres brancas, negras, índias e da elite em diferentes temporalidades. Margareth Rago ${ }^{14}$ remete à constatação de que, diferentemente do que muitas pessoas pensavam, as mulheres sempre participaram de várias ações e em diferentes espaços ${ }^{15}$. São obras que analisam fontes e trajetórias

\footnotetext{
10 SOIHET, Raquel; PEDRO, Joana Maria. A emergência da pesquisa da história das mulheres e das relações de gênero, p. 284.

${ }^{11}$ PEDRO, Joana Maria. Relações de gênero como categoria transversal na historiografia contemporânea. Revista Topoi, v. 12, n. 22, 2011, p. 270.

12 PERROT, Michelle. Minha História das Mulheres. São Paulo, Editora Contexto, 2015.

13 SCOTT, Joan. História das Mulheres. In: BURKE, Peter (Org.). A Escrita da História: novas perspectivas. São Paulo: UNESP, 1992.

${ }^{14}$ RAGO, Margareth Luzia. As mulheres na historiografia brasileira. In: SILVA, Zélia Lopes (Org.). Cultura Histórica em Debate. São Paulo: UNESP, 1995.

${ }^{15}$ SANTOS, Geilza da Silva. Mulheres quilombolas: Território, gênero e identidade na Comunidade Negra Senhor do Bonfim, Areia/PB (2005-2018). 2018. Dissertação (Mestrado em História) - Centro de Ciências Humanas, Letras e Artes, Universidade Federal da Paraíba, João Pessoa-PB, p. 23-24.
} 
femininas em vários contextos, contribuindo para se pensar a história das mulheres negras, brancas, indígenas, da elite e do campo.

A partir da década de 1980, inauguram-se novas pesquisas no campo da escravidão abordando as vivências de homens e mulheres. Vários trabalhos sob o enfoque da história social ressaltaram a história dos negros escravizados, as suas lutas e resistências. Um dos estudos pioneiros no que tange aos estudos sobre as mulheres negras é o da historiadora e antropóloga Sônia Maria Giacomoni ${ }^{16}$. Além de analisar as histórias das mulheres negras no Brasil, Giacomoni aborda as atividades que elas desenvolviam e as estratégias que seriam utilizadas por elas para proporcionar melhores condições de vida às suas famílias. Outra abordagem de grande valia para se pensar a mulher negra se encontra nos estudos da historiadora Maria Odila Leite ${ }^{17}$, que estudou sobre o cotidiano das negras quituteiras, salientando as suas lutas pela sobrevivência no espaço urbano.

Outra autora importante nos estudos sobre a mulher negra é Lélia Gonzalez ${ }^{18}$, que analisou o lugar destas mulheres na sociedade brasileira com o intuito de perceber a sua importância e que assim se descubra o leque de possibilidades que o estudo sobre essas mulheres revelam sobre a nossa cultura. Apontou também a mulher negra, anônima, como sendo o sustentáculo da sua família, tendo o papel mais importante "exatamente porque com sua força e corajosa capacidade de luta pela sobrevivência, transmite-nos a nós, suas irmãs mais afortunadas, o ímpeto de não nos recusarmos à luta pelo nosso povo" ${ }^{19}$.

Nos estudos paraibanos sobre a mulher negra, destacamos a historiadora Solange Pereira da Rocha, cuja dissertação versa sobre as condições das mulheres escravizadas na Província da Paraíba ${ }^{20}$. É extensa a lista de trabalhos escritos pela historiadora paraibana que vem trazendo ao debate a questão das mulheres negras. E como ela bem nos coloca em $\operatorname{artigo~}^{21}$, as abordagens que privilegiam o estudo da temática relativa às mulheres

\footnotetext{
${ }^{16}$ GIACOMINI, Sônia Maria. Mulher e Escrava: uma introdução histórica ao estudo da mulher negra no Brasil. Petrópolis: Vozes, 1985.

${ }^{17}$ DIAS, Maria Odila Leite da Silva. Cotidiano e Poder em São Paulo no séc. XIX. São Paulo: Brasiliense, 1984.

${ }^{18}$ GONZALEZ, Lélia. A mulher negra na sociedade brasileira. In: LUZ, Madel Therezinha. O Lugar da Mulher: estudos sobre a condição feminina na sociedade atual. Rio de Janeiro: Edições Graal, 1982.

${ }^{19}$ GONZALEZ, Lélia. A mulher negra na sociedade brasileira, p. 103-104.

${ }^{20}$ ROCHA, Solange Pereira da. Na Trilha do Feminino: condições de vida das mulheres escravizadas na província da Paraíba, 1828-1888. 2001. Dissertação (Mestrado em História) - Centro de Filosofia e Ciências Humanas, Universidade Federal de Pernambuco, Recife-PE.

${ }^{21}$ ROCHA, Solange Pereira da. Antigas personagens, novas histórias: memórias e histórias de mulheres escravizadas na Paraíba oitocentista. Brasília: Secretaria Especial de Políticas para as Mulheres da Presidência da República, 2006, p. 173.
} 
escravizadas têm sido estimuladas pelo avanço da história social da escravidão, de um "novo olhar" direcionado para o universo dos escravizados.

Outra obra importante para a história das mulheres negras é o livro Mulheres Negras no Brasil escravista e da pós-emancipação ${ }^{22}$, que congrega vários escritos que analisam o lugar da mulher negra, escrava ou liberta em diversas temporalidades e espaços. A coletânea busca perceber as mulheres como protagonistas das mais diversas histórias. Dentre seus capítulos, destacamos o de Solange Rocha: Mulheres escravizadas na Paraíba oitocentista: Trabalho, contradições e lutas ${ }^{23}$, que aborda três mulheres escravizadas em décadas diferentes do século XIX, evidenciando as suas lutas pela liberdade na Província do Norte.

Essas obras, entre outras, são de extrema importância para refletir sobre as mulheres negras, seu cotidiano e suas vivências e, portanto, as perceber enquanto "sujeitos da história". No entanto, é preciso ressaltar a luta de ativistas negras em busca de uma visibilidade na tentativa de inserção da discussão sobre as mulheres negras na sociedade brasileira, sendo essenciais para se pensar o "lugar" que estas ocupam.

\section{Contribuições do feminismo negro}

Desde a década de 1970, os estudos do feminismo negro buscam analisar e compreender as especificidades das mulheres negras como sujeitos históricos, bem como apontar o lugar de invisibilidade que essas ocuparam por muitos anos nas pesquisas, e mais precisamente na historiografia. Estudos, como os evidenciados acima, que além de analisar os papéis que as mulheres negras ocupam nas relações sociais, evidenciam as vozes historicamente silenciadas.

O feminismo negro, segundo Lélia Gonzalez ${ }^{24}$, teria uma diferença específica em relação ao feminismo ocidental: a solidariedade, fundada em uma experiência histórica em comum. A busca por visibilidade destas mulheres dentro do movimento feminista ganhou maior força a partir da segunda onda do feminismo, entre 1960 e 1980, em que as mulheres negras passaram a apontar a questão do racismo como pauta, atentando para

\footnotetext{
22 XAVIER, Giovana; FARIAS, Juliana Barreto; GOMES, Flávio (Orgs.). Mulheres negras no Brasil escravista e do pós-emancipação. São Paulo: Selo Negro Edições, 2012.

23 Cf.: ROCHA, Solange Pereira da. Mulheres escravizadas na Paraíba Oitocentista: trabalho, contradições e lutas por liberdade. In: XAVIER, Giovana; FARIAS, Juliana Barreto.; GOMES, Flávio. (Org.). Mulheres Negras no Brasil escravista e do pós-emancipação. São Paulo: Selo Negro, 2012.

${ }^{24}$ GONZALEZ, Lélia. A mulher negra na sociedade brasileira.
} 
um fato importante acerca da exclusão da mulher negra nos textos e no discurso do movimento feminista no Brasil.

O movimento feminista ou de mulheres não se atentava para a questão racial e não via a grande questão das mulheres negras que sofriam além do preconceito de gênero, o ligado à sua cor e, portanto, não percebiam as questões específicas destas em vários âmbitos: trabalho, educação, saúde, etc. Apesar da maioria dos textos tratarem das relações de dominação sexual, social e econômica em que a mulher foi submetida, bem como da situação das mulheres de camadas mais pobres, não atentavam para o fato da opressão racial. Lélia Gonzalez aponta:

\begin{abstract}
As categorias utilizadas são exatamente aquelas que neutralizam o problema da discriminação racial e, consequentemente, o do confinamento a que a comunidade negra está reduzida. A nosso ver, as representações sociais manipuladas pelo racismo cultural também são internalizadas por um setor que, também discriminado, não se apercebe que, no seu próprio discurso, estão presentes os mecanismos da ideologia do branqueamento e do mito da democracia racial ${ }^{25}$.
\end{abstract}

Gonzalez parte de sua própria experiência dentro do feminismo, em que denunciava essas questões. Salienta que quando se tratava das lutas pelas exigências quanto à exploração da mulher, do operariado e etc., existia uma unanimidade das participantes de esquerda quanto a essas denúncias, mas quando se começava a falar sobre as pautas de racismos e suas práticas em termos de mulher negra, não havia mais unanimidade. E assim constatava, além de um atraso político em grupos considerados mais progressistas, uma negação do racismo para ocultar outra problemática: a exploração da mulher negra pela branca. Rompendo com o discurso feminista tradicional, centrado numa perspectiva europeia e/ou norte-americana na opressão da questão do gênero, as mulheres negras passaram a se organizar politicamente no intuito de dar visibilidade àquelas a quem os direitos básicos foram negados.

Ao pensar os direitos adquiridos pelas mulheres ao longo dos anos, como o direito ao voto, elevação do grau de instrução, avanços no campo da sexualidade, liberdade de expressão e direitos reprodutivos, a historiadora Bebel Nepomuceno alerta para o fato de que tal trajetória não se aplica do mesmo modo a todas as mulheres:

Mulheres de grupos distintos viveram-na de maneiras diferentes e ritmos variados. Partiram de patamares desiguais e, no desenrolar dos acontecimentos, não caminhavam juntas nem no mesmo passo, com determinadas situações de nítidos privilégios para umas e exclusão de outras ${ }^{26}$.

\footnotetext{
${ }^{25}$ GONZALEZ, Lélia. A mulher negra na sociedade brasileira, p. 100.

${ }^{26}$ NEPOMUCENO, Bebel. Mulheres Negras - "Protagonismo Ignorado". In: PINSKY, Carla Bassanezi; PEDRO, Joana Maria (Org.). Nova História das Mulheres. São Paulo: Editora Contexto, 2013.
} 
Assim sendo, por exemplo, se uma das lutas do feminismo era modificar a ideia da mulher enquanto rainha do lar, desmistificar a ideia de fragilidade, de que mulheres elas estavam falando? Onde se inseria a mulher negra nesse contexto? Tendo em vista que faziam parte da mão-de-obra, que durante vários anos foram escravas no eito ou como mucamas, ou mulheres pobres, sós ou chefes de família que procuravam meios de sobreviver e sustentar suas famílias, a partir de ocupações domésticas (doces, salgados, lavagem de roupas) traziam para os espaços públicos suas atividades: as quitandeiras, lavadeiras, artesãs, vendedoras de tabuleiros ${ }^{27}$, por exemplo. Ou seja, enquanto as mulheres estavam querendo o direito de trabalhar e de ir para as ruas, as mulheres negras já faziam isso há tempos. Portanto, havia questões díspares entre a realidade da mulher branca e da mulher negra.

Assim, o feminismo negro surgiu como uma resposta à lacuna encontrada no feminismo, partindo da iniciativa de ativistas negras. Bebel Nepomuceno destaca duas intelectuais ativistas: Lélia Gonzalez e Beatriz Nascimento como peças chaves no processo que ficou conhecido como o "enegrecimento do feminismo" 28 . Na busca constante de inserir as questões das mulheres negras no movimento feminista, bem como no movimento negro, para que estes se voltassem também para as questões de raça, gênero e classe. Assim, cada vez mais essas mulheres negras vão trilhando uma “autodeterminação política", resultando na formação de várias organizações feministas negras no Brasil. Entre alguns grupos criados de mulheres negras estão o Aqualtune (1973), Luíza Mahin (1980) e o Grupo de Mulheres Negras do Rio de Janeiro (1982), mas sempre interligados ao movimento negro. Desse modo, foram surgindo outros grupos em diversas regiões ao longo dos anos, destacamos na Paraíba o Bamidelê - Organização de Mulheres Negras na Paraíba, formado em 2001 e que atua contra as desigualdades sociais, raciais e de gênero ${ }^{29}$.

No interior do feminismo a articulação entre gênero e pós-colonialismo, por exemplo, parte da premissa de que a partir das margens é possível ler melhor o mundo e elaborar um projeto crítico e inovador. Buscando a partir dos colonizados, "recuperar" as "vozes baixas" da história. Além do que, esta abordagem focaliza as interseções entre

\footnotetext{
${ }^{27}$ Maria Odila Leite aborda sobre o cotidiano das negras quitandeiras salientando suas lutas pela sobrevivência no espaço urbano. Cf.: DIAS, Maria Odila Leite da Silva. Quotidiano e Poder em São Paulo no séc. XIX, 1984.

${ }^{28}$ NEPOMUCENO, Bebel. Mulheres Negras - "Protagonismo Ignorado", p. 400.

${ }^{29}$ SANTOS, Geilza da Silva. Mulheres quilombolas: Território, gênero e identidade na Comunidade Negra Senhor do Bonfim, Areia/PB (2005-2018), p. 25.
} 
gênero, raça/etnia e classe. No entanto, para que estas perspectivas fossem contempladas foi necessária a luta das mulheres negras, para que outras questões fossem levadas em consideração dentro do feminismo, como assinalamos acima. Como bem pontua Kimberlé Crenshaw, de que várias situações tornam as mulheres negras invisíveis e os seus problemas, às vezes, ficam subincluídos. É como se, embora possa se falar sobre todos os problemas enfrentados pelas mulheres, suas especificidades não devessem ser discutidas. Muitas das questões não incluídas na agenda das feministas afetam especificamente mulheres negras. As análises nem sempre consideram como a raça ou a classe social contribuem para gerar as desigualdades ${ }^{30}$.

Ao repensar historicamente a categoria "mulher" de modo não universal e de forma crítica, muitas intelectuais negras vêm apontando a importância de outras possibilidades. Angela Davis, por exemplo, já evidenciava a questão das opressões estruturais como indissociáveis, antes mesmo do conceito de interseccionalidade ser cunhado $^{31}$. Em seu livro Mulher, raça e classe $^{32}$, analisa o modo de produção escravista e capitalista nos possibilitando observar como as diversas opressões se intercruzam, além de fundamentar as origens das lutas feministas e antirracistas. Desse modo, seu livro se torna importante para as feministas negras preocupadas em compreender os múltiplos efeitos da interseccionalidade entre os marcadores de classe, raça e sexualidade. Um dos fatores assinalados no livro é a opressão sofrida pelas mulheres negras, trazendo questões complexas que afetam também a esfera privada, como os direitos sexuais e reprodutivos. De maneira geral, Davis preconiza que as opressões devem ser percebidas entrelaçadas pelo gênero e pela raça, derivadas tanto da exploração de trabalho, como também de subjetividades e dos corpos das mulheres negras.

Pensando o lugar da mulher negra na força social e nas relações raciais, a exemplo, Lélia Gonzalez traz a constatação de que na medida em que exista uma divisão racial e sexual do trabalho, não é difícil perceber o processo de tríplice discriminação sofrido pela mulher negra (raça, classe e sexo), bem como seu lugar na força de trabalho. Ora, os estereótipos gerados pelo racismo e sexismo as colocam no nível mais baixo de opressão e as condicionam à falta de perspectiva e possibilidades de alternativas. Desse modo,

\footnotetext{
${ }^{30}$ CRENSHAW, Kimberlé. A interseccionalidade na discriminação de raça e gênero. Brasília: UNIFEM, 2004. Disponível em: <http://www.acaoeducativa.org.br/fdh/wp-content/uploads/2012/09/KimberleCrenshaw.pdf $>$, acesso em: 20 abr. 2018, p. 14.

${ }^{31} \mathrm{O}$ termo interseccionalidade foi cunhado na década de 80 pela teórica feminista estadunidense Kimberlé Crenshaw.

${ }^{32}$ DAVIS, Ângela. Mulheres, raça e classe. São Paulo: Boitempo, 2016.
} 
partindo do pressuposto da interseccionalidade, precisamos identificar melhor o que acontece quando diversas formas de discriminação se combinam e afetam as vidas de determinadas pessoas ${ }^{33}$.

Portanto, destacamos a importância do feminismo negro ao trazer para os estudos sobre as mulheres, pautas até então marginalizadas. A partir destas perspectivas e destaque para as mulheres negras, abordaremos sobre a situação da mulher no município de Areia no período pós-abolição, com ênfase para as mulheres negras que viveram na região hoje denominada de Comunidade Negra Senhor do Bonfim.

\section{As mulheres da Comunidade Negra Senhor do Bonfim}

A Comunidade Negra do Senhor do Bonfim recebeu a certificação como comunidade quilombola em 18 de abril de 2005, expedida pela Fundação Cultural dos Palmares. Está localizada na zona rural do município de Areia, no estado da Paraíba. Atualmente ocupa uma área de aproximadamente 100 hectares dentro da propriedade Engenho Bom Fim ${ }^{34}$, localizada no distrito de Cepilho. É formada por dois grupos familiares: os "Faustino" e os "Pedro ou de Maria", sendo ao todo 25 famílias que convivem nessa região. Esses grupos, além de manter laços de parentesco, existe uma grande afinidade entre eles, tendo em comum uma história baseada no trabalho árduo no engenho, nas plantações de cana e agave do Bom Fim. As primeiras famílias chegaram à região no início do século $\mathrm{XX}$ e se estabeleceram naquela região, na condição de moradores ${ }^{35}$. Portanto, a comunidade foi formada em domínios de particulares e viviam como subordinados ao proprietário.

Com o fim da escravidão, muitos negros tornaram-se moradores/agregados. A abolição, como já foi dito, não trouxe melhoria nas condições de vida do negro. Sendo a partir daí que surgem novas formas de sujeições para esses, como é o caso do "caba do eito" ou do morador de condição. Assim, os senhores de engenho permitiam que os agricultores sem terra para produzir, vivessem no interior de seus territórios. O historiador Pedro Nicácio Souto analisando o pós-abolição em Areia através dos censos, dos processos criminais e dos jornais que circularam no município, busca mostrar como era a

\footnotetext{
${ }^{33}$ CRENSHAW, Kimberlé. A interseccionalidade na discriminação de raça e gênero, p. 11.

${ }^{34}$ A propriedade do Engenho em cartório tem por nome Bom Fim, mas atualmente a comunidade se intitula com a grafia de Bonfim. Assim, no texto será utilizado segundo esse critério para identificar a comunidade e a propriedade.

35 Os senhores de engenho permitiam que os trabalhadores tivessem direito a um pequeno sítio, onde poderiam ter a sua pequena lavoura de subsistência e ao mesmo tempo eram obrigados a trabalhar para o senhor de engenho um certo número de dias.
} 
vida dos trabalhadores após a abolição, inclusive os negros libertos nos finais do século XIX e início do XX. Ressaltando a "cabra de eito", como ficou conhecido o trabalhador de engenho no pós-abolição que vivia situação simétrica ao período escravocrata, sofrendo duras penas no seu labor cotidiano ${ }^{36}$.

Ao apontar a condição de morador como prática comum no município de Areia nesse período, nos deparamos com essa prática no Engenho Bom Fim. O engenho foi adquirido por Honorato Barbosa em 1913, no entanto, não se sabe ao certo em que ano o Senhor João Faustino, primeiro morador, chegou nessa propriedade. Para tanto, seu primeiro filho nasceu já na propriedade, isso por volta de 1920, e sendo assim, a família dos Faustino está estabelecida nessas terras há mais de 95 anos. Dessa forma, vinte e poucos anos após a abolição, esse senhor viria a morar nessa região na condição de morador. Não se sabe de onde ele veio, pois a memória dos Faustino foi constituída a partir da vida neste lugar e nos resta a dúvida: quem seria João Faustino dos Santos? Um ex-escravizado ou descendente de escravizados do município de Areia ou de outra região à procura de melhores condições de vida?

Na memória dos moradores do Bonfim e nas informações contidas no relatório antropológico, apesar da ênfase ao primeiro morador, chegara também no mesmo período uma mulher conhecida como Dona Mariquinha. Sua neta, Dona Pirriu ${ }^{37}$, nos conta que não tem registros fotográficos de Dona Mariquinha e nem seus documentos, mas através de suas memórias, nos conta a "história" dessa senhora que seria uma das primeiras moradoras do Bom Fim. Dona Mariquinha é sempre lembrada nas recordações de Dona Pirriu e da matriarca do grupo, Dona $\mathrm{Biu}^{38}$, fazendo menção que essa senhora vivia do trabalho laborioso do campo para sustentar seus filhos. Nascida em 1886, procedente da Barra do Camará, também chamado de Barra dos $\operatorname{Negros}^{39}$, veio para a região do Bonfim

\footnotetext{
36 SOUTO, Pedro Nicácio. Areia: uma "aldeia" negra paraibana de fins do século XIX e as primeiras décadas do século XX. 2015. Dissertação (Mestrado em História) - Centro de Humanidades, Universidade Federal de Campina Grande, Campina Grande-PB, p. 18.

${ }^{37}$ Moradora da Comunidade, conhecida como Dona Pirriu, 70 anos, ensino fundamental incompleto, mora na comunidade desde que nasceu, em 1949, viúva de Floriano Faustino (neto do primeiro morador João Faustino) e neta de uma das primeiras moradoras da comunidade.

38 Moradora da Comunidade, considerada a matriarca do grupo, 77 anos, viúva, católica, ensino fundamental incompleto, agricultora, rezadeira, trabalhou na casa grande como lavadeira. Veio morar na região do Bom Fim quando casou com o senhor Miguel Pedro.

${ }^{39}$ Se vincula de duas maneiras ao Bom Fim e à comunidade negra que hoje nele vive: de um lado sabemos que parte desta área foi incorporada ao Bom Fim e de outro sabemos que muitos dos seus moradores compuseram a mão-de-obra que tocou o engenho durante muitas décadas e que compõem hoje a Comunidade Negra Senhor do Bonfim. Cf.: BRASIL. Relatório Antropológico de Reconhecimento e Delimitação do Território da Comunidade Negra Senhor do Bonfim. Instituto Nacional de Colonização e Reforma Agrária - INCRA, Superintendência Regional - Paraíba, João Pessoa, n. 18, 2007, p. 51.
} 
com seus filhos, provavelmente em meados da década de $1920^{40}$. Desse modo, gostaríamos de analisar o contexto em que essa senhora estava inserida, recuando, primeiramente, ao censo de 1872 que traz uma visão mais detalhada do munícipio de Areia e ajuda a compreender que mesmo após a abolição, anos depois da realização desta, a situação da população negra não mudou com relação às suas funções na sociedade.

Quadro 1 - População de Areia em 1872

\begin{tabular}{|c|c|c|c|c|c|}
\hline \multicolumn{1}{|c|}{ Sexo } & População & Brancos & Pardos & Pretos & Caboclos \\
\hline Homens livres & 11902 & 3385 & 7705 & 597 & 215 \\
\hline Mulheres livres & 12223 & 3578 & 7923 & 553 & 169 \\
\hline Homens escravos & 692 & - & 259 & 433 & - \\
\hline Mulheres escravas & 732 & - & 306 & 426 & - \\
\hline Total & $\mathbf{2 5 . 5 4 9}$ & 6.963 & 16.193 & 2.009 & 384 \\
\hline
\end{tabular}

Fonte: Censo de 1872

Contando com uma população de 25.549 , sendo $94,42 \%$ livres e $5,57 \%$ escravos, Areia teria sido nesse período um local de predominância branca? Ou teria sido a "aldeia negra" que o historiador Souto ${ }^{41}$ denomina? No quadro acima, podemos constatar que existem homens e mulheres livres que foram identificados como "pretos", o que já nos daria um percentual de aproximadamente 7,86\% de negros em Areia. Mas e os pardos? A designação de pardo "era usada, antes, como forma de registrar uma diferenciação social, variável conforme o caso, na condição mais geral de não-brancos" ${ }^{\text {42 }}$. Os pardos estariam mais "próximos" dos brancos e os homens livres com ascendência africana, eram considerados pardos no século XIX.

Assim, vemos uma população negra equivalendo a 71,24\%, o que seria mais da metade da população. No quadro geral da Paraíba em relação à população, Solange Rocha nos apresenta que considerando os dados por cor se tinha uma população de maioria negra (parda e preta) "que somava 221.938 (188.241 pardos e 33.697 pretos), atingindo o percentual de 59\%, superando, assim, o número dos brancos, que atingiram o número de

\footnotetext{
40 BRASIL. Relatório Antropológico de Reconhecimento e Delimitação do Território da Comunidade Negra Senhor do Bonfim, p. 46.

41 SOUTO, Pedro Nicácio. Areia: uma "aldeia" negra paraibana de fins do século XIX e as primeiras décadas do século XX.

42 SOUTO, Pedro Nicácio. Areia: uma "aldeia" negra paraibana de fins do século XIX e as primeiras décadas do século XX, p. 44.
} 
$139.988(37,2 \%)^{43}$, o que também nos mostra uma Paraíba com grande contingente de negros.

Infelizmente alguns censos posteriores, de 1890 e de 1900, não nos trazem detalhes dessa população, apenas a questão do sexo, mas não seria possível que um contingente tão grande de negros, como vimos no primeiro recenseamento desaparecesse. Em relação à população nos censos analisados, pudemos notar que a população feminina, exceto em 1900, continuou sendo maioria nessa cidade como mostra o gráfico abaixo.

Gráfico 1 - População masculina e feminina de 1872-1920

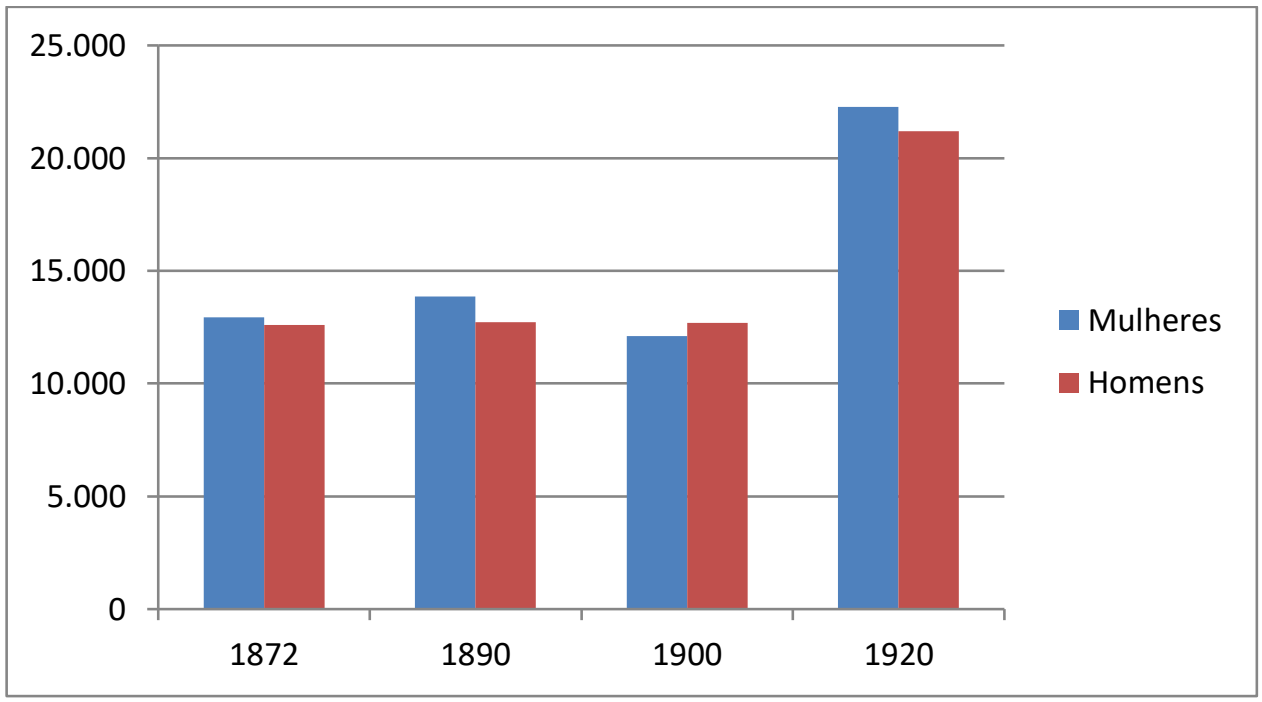

Fonte: IBGE - censos de 1872, 1890, 1900 e 1920

Se levarmos em consideração o censo de 1872, já que os demais não apresentam a "cor" dessa população e vendo esse aumento populacional, temos entre essas mulheres um grande contingente de negras. Além do que temos uma Areia ainda ligada ao campo, mesmo que esse aumento populacional tenha se dado tanto no campo quanto na cidade. O censo de 1872 nos traz mais informações sobre a vida dessas mulheres, a partir do qual supomos que nos anos seguintes, mesmo após a abolição, a vida dessas mulheres negras não tiveram alterações significativas, continuando a exercer funções idênticas de quando eram escravas.

Em relação à população feminina, no ano de 1872 vemos certa preponderância, mesmo que pequena, em relação aos homens, contanto com 50,70\% da população, sendo

\footnotetext{
${ }^{43}$ ROCHA, Solange Pereira da. Gente Negra na Paraíba Oitocentista: População, Família e Parentesco Espiritual. 2007. Tese (Doutorado em História) - Centro de Filosofia e Ciências Humanas, Universidade Federal de Pernambuco, p. 140.
} 
94,34\% livre e 5,65\% escrava. No quesito "raça" em relação às mulheres (12.955), temos $27,61 \%$ brancas, $61,15 \%$ pardas, $4,26 \%$ pretas e $1,30 \%$ caboclas em relação às mulheres livres; já com relação às mulheres escravas, temos 2,36\% pardas e 3,28\% pretas. As mulheres negras, quer fossem escravas, libertas ou livres, sempre trabalharam seja em ambientes rurais ou urbanos, ocupando as mais variadas funções, sendo que dessas mulheres, 99,73\% eram analfabetas, o que não se diferenciava do homem negro que contava com essa mesma porcentagem.

No quesito profissões esse censo nos traz os dados dessas mulheres escravizadas. Do total de 732 escravas, 10 (1,3\%) eram costureiras, 421 (57,51\%) eram domésticas, $254(34,69 \%)$ lavradoras. No entanto, é preciso salientar que esses serviços domésticos também ocorriam na zona rural, nas casas-grandes dos engenhos, por exemplo. Vemos assim, duas categorias que Lélia Gonzalez aborda: a trabalhadora do eito e a mucama e como esses papéis foram se perpetuando no mundo do trabalho mesmo após a abolição ${ }^{44}$. Analisando as "escravas do lar", a historiadora Flávia Fernandes de Souza observa a cidade do Rio de Janeiro através do recenseamento de 1872 também constatando que a presença de mulheres escravas nas atividades domésticas era preponderante, além de mulheres livres e libertas que ocupavam consideravelmente essas funções ${ }^{45}$.

No município de Areia, em 1872, também constatamos essas mulheres ocupando principalmente essas funções. Do número total de mulheres livres (12.223), 7.923 se diziam pardas e 553 negras e as ocupações majoritárias destas eram em serviços domésticos e como lavradoras. Dessa maneira, podemos pensar que essas funções foram importantes para essas mulheres livres e libertas nos últimos anos da escravidão. Para Souza $^{46}$, ao longo do Oitocentos, em lugares diferentes do Brasil, grande parte das mulheres trabalhadoras ocupavam as funções consideradas típicas da condição feminina, ou seja, as atividades ligadas ao lar, mesmo enquanto vendedoras de alimentos, era um desdobramento de atividades advindas do lar.

Mas, gostaríamos de salientar que algumas mulheres negras viviam do trabalho laborioso do campo. Beatriz Nascimento ${ }^{47}$ constata a estrutura hierarquizada da sociedade

\footnotetext{
${ }^{44}$ GONZALEZ, Lélia. A mulher negra na sociedade brasileira.

45 SOUZA, Flavia Fernandes de. Escravas do lar: as mulheres negras e o trabalho doméstico na Corte Imperial. In: XAVIER, Giovana; FARIAS, Juliana Barreto; GOMES, Flávio (Orgs.). Mulheres negras no Brasil escravista e do pós-emancipação. São Paulo: Selo Negro Edições, 2012.

46 SOUZA, Flavia Fernandes de. Escravas do lar: as mulheres negras e o trabalho doméstico na Corte Imperial, p. 252.

${ }^{47}$ NASCIMENTO, Beatriz. A mulher negra na sociedade brasileira. In: RATTS, Alex. Eu sou Atlântica: sobre a trajetória de Beatriz Nascimento. São Paulo: Imprensa Oficial do Estado de São Paulo: Instituto Kuanza, 2007.
} 
brasileira na época colonial em que diversos grupos desempenharam papeis diferentes, tendo por um lado o senhor de terras que detinha todo poder econômico e político, e por outro os escravos que eram a força de trabalho efetivo e os homens e mulheres livres que viviam em condições precárias. Portanto, é uma estrutura patriarcal que permeava toda estrutura da sociedade colonial nesse contexto em que a mulher branca era vista como esposa e mãe e que deveria se dedicar ao marido e filhos e à casa. Em contraponto, temos a mulher negra, tendo papel semelhante ao homem, ou seja, com papel ativo na sociedade, que enquanto escrava trabalhava na casa grande, no campo, nos engenhos, além de ser a "mãe em potencial" de novos escravos e assim, junto com o escravo homem, era o suporte do sistema escravocrata.

Maria Lucia de Barros Mott, em estudo acerca da resistência da mulher no período da escravidão, aponta que foram poucos os trabalhos que a mulher escravizada não realizou no Brasil, quando "além daquelas atividades que tinham por obrigação cumprir, o mais comum era acumularem várias outras ao mesmo tempo ${ }^{48}$ ". Seja nos engenhos ou nas roças, havia uma diferenciação de funções entre homens e mulheres nas grandes propriedades, ficando estas com o trabalho "mais leve". No entanto, nas mais pobres e pequenas propriedades não havia essa divisão sexual em relação aos escravizados, pois utilizavam as escravas em qualquer tarefa, mesmo as consideradas mais pesadas. "Elas eram empregadas na manufatura do açúcar, no descaroçamento do algodão, no beneficiamento da mandioca, na limpeza da roça de milho, na colheita de produtos silvestres, na ordenha"49.

Dona Mariquinha é um exemplo de como a mulher negra ocupara as mais variadas funções na sociedade. Fora abandonada por seu marido e veio para a região acompanhada pelos seus oito filhos, criando-os na região, não abandonando nenhum, como nos conta sua neta. Trabalhou nas terras do Bonfim até à velhice e sustentou toda a sua família, juntamente com seu filho mais velho. Dona Pirriu nos conta que sua avó trabalhava amassando barro, além de exercer outras funções:

Ela trabalhava pra finado fulano. (...) Quando dava quatro da madrugada ela já vinha com capim, ela andava com uma cordinha amarrada na cintura, era pequeninha, mas sustentou os filhos tudinho. (...) Aí criou os filhos tudinho aqui dentro, separada, não abandonou nenhum, criou tudinho aqui dentro, trabalhava na enxada. Ela trabalhou amassando barro, na casa de farinha, trabalhou demais ${ }^{50}$.

\footnotetext{
${ }^{48}$ MOTT, Maria Lucia de Barros. Submissão e Resistência: a mulher na luta contra a escravidão. São Paulo: Contexto, 1998, p. 20.

${ }^{49}$ MOTT, Maria Lucia de Barros. Submissão e Resistência: a mulher na luta contra a escravidão, p. 21.

${ }^{50}$ Entrevista concedida à autora por Josefa Mariano Faustino dos Santos, realizada em: mar. 2017 (1h $15 \mathrm{~min}$.).
} 
Nas memórias dessa senhora, o sofrimento e as dificuldades enfrentadas na região são sempre ressaltadas, sendo elas que constituem a história do grupo ${ }^{51}$. Ao lembrar dessa figura tão presente em sua trajetória, Dona Pirriu recorda sua fisionomia frágil e ao mesmo tempo tão forte. Dona Mariquinha é um exemplo do que aconteceu com muitas mulheres negras, abandonadas à própria sorte e tendo que sustentar sozinha seus filhos. Dona Pirriu não conseguiu lembrar o nome do seu avô, mas nos conta que era "homem muito ignorante" e que tratava sua avó muito mal ${ }^{52}$. Mesmo assim, nos diz que foi seu avô que a abandonara e assim, acreditamos que mesmo sendo maltratada, Dona Mariquinha não o deixou, consequentemente devido à grande quantidade de filhos e não ser originária da região, veio de Campina Grande, ${ }^{53}$ segundo sua neta.

Estamos falando do início do século XX, quando predominava o discurso de inferioridade e submissão das esposas. No entanto, o marido a deixara e ela tornou-se a chefe da família e apesar de todos os percalços, criou todos os seus filhos e trabalhou até à velhice. Seus filhos começaram a trabalhar bem cedo para ajudar no complemento das despesas da casa. Dona Pirriu relembra de sua avó como uma mulher forte que enfrentou sozinha a criação dos filhos e o sustento da casa e que trabalhou até quando pôde nas terras do Bonfim.

Teresinha Bernardo em estudo acerca da cidade de São Paulo no início do século $\mathrm{XX}$, e em que uma das suas fontes são os relatos das mulheres negras, salienta que muitas delas eram chefes de suas famílias e muitas optaram por não casar, seja porque já faziam tudo sozinhas, logo não precisariam destes, ou por achar que homem em casa atrapalharia suas vidas ou até pelo fato de não querer casar com negros ${ }^{54}$. Mas, acima de tudo podemos perceber a força dessas mulheres negras, que não difere de Dona Mariquinha quando sua neta ou Dona Biu a descreve, ou pelo fato que mesmo após ser abandonada, não foi à procura de um novo parceiro para ajudá-la, seguiu sozinha, constituindo uma família

\footnotetext{
51 Nas entrevistas pudemos constatar que a história de sofrimentos no Engenho Bom Fim é sempre ressaltada e rememorada, mesmo que os indivíduos não tivessem presenciado algumas situações. Evidenciando aquilo que o Pollak (1992, p. 201) pontua: "podem existir acontecimentos regionais que traumatizaram tanto, marcaram tanto uma região ou um grupo, que sua memória pode ser transmitida ao longo dos séculos com altíssimo grau de identificação", as histórias contadas pelos mais velhos constroem a memória do grupo, unindo assim as gerações com uma história em comum, marcada, principalmente, pela ancestralidade e sofrimentos na região.

52 Dona Pirriu não conheceu seu avô, deduzimos que essas informações foram dadas por sua avó, tios e pai.

${ }^{53}$ O município de Campina Grande está situado na Mesorregião Geográfica do Agreste Paraibano, na Zona Centro Oriental da Paraíba, no planalto da Borborema.

${ }^{54}$ BERNARDO, Teresinha. Memória em branco e negro: olhares sobre São Paulo. São Paulo: EDUC: Editora UNESP, 1998.
} 
matrifocal. Prática essa que Bernardo constata também no início do século XX na cidade de São Paulo entre as mulheres negras pesquisadas.

Na Comunidade Negra Senhor do Bonfim pudemos constatar no pós-abolição a perpetuação de duas práticas encontradas no recenseamento de 1872: a lavradora e a doméstica que se perpetuou até à conquista enquanto comunidade quilombola. Duas moradores do Engenho Bonfim trabalhavam na casa grande como domésticas: Jaceli e Maria. Dona Biu, a matriarca da família "Pedro de Maria", nos conta que trabalhava de lavadeira para a proprietária do Engenho. As demais mulheres ficavam responsáveis pelos roçados de casa, mas se lembram que muitas vezes tinham que ajudar os homens ${ }^{55}$. As mulheres trabalharam lado a lado dos seus pais e maridos, cortando cana, lenha, puxando agave e cuidado dos roçados. Os homens recebiam um salário irrisório, enquanto as mulheres não recebiam nada. Assim constatamos o alerta de Nepomuceno: "entre as mulheres negras, acostumadas aos percalços da vida, não havia muito espaço para a imagem da esposa passiva, submissa ao marido e dedicada exclusivamente ao lar" ${ }^{" 56}$. Quando algumas conseguiam ir para cidade grande, principalmente João Pessoa e São Paulo, como nos diz Dona Biu ${ }^{57}$, conseguiam apenas empregos como domésticas, como o caso de suas filhas.

Teresinha Bernardo, acerca de algumas mulheres negras no início do século XX, salienta a precarização do trabalho para essas mulheres, ocupando cargos de domésticas, lavadeiras ou vendedoras. A mobilidade social para essas mulheres negras era algo muito além. Nas palavras dessa autora, através da análise de alguns depoimentos: "nessas lembranças ressalta o descrédito do próprio grupo a respeito da mobilidade ocupacional; mais do que isto, ressalta a discriminação que as mulheres negras sofriam, daí o descredito

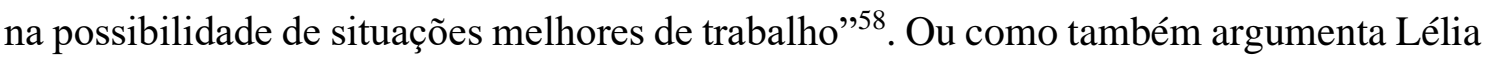
Gonzalez ao pensar a mulher negra e a falta de perspectiva em relação à possibilidade de novas alternativas, pois "ser negra, mulher no Brasil, repetimos, é ser objeto de tripla discriminação, uma vez que os estereótipos gerados pelo racismo e sexismo as colocam no mais baixo nível de repressão" ${ }^{59}$.

\footnotetext{
55 Angela Davis (2016), ao analisar as mulheres negras nos Estados Unidos no século XIX, aponta que estas eram vistas como "unidades rentáveis de trabalho" e assim como os homens, em sua maioria, trabalhavam no campo. Situação esta que não se difere no Brasil no pós-abolição, quando as mulheres continuaram no trabalho laborioso do campo.

${ }^{56}$ NEPOMUCENO, Bebel. Mulheres Negras - "Protagonismo Ignorado", p. 387.

${ }^{57}$ Entrevista concedida à autora por Severina Gomes de Sousa, realizada em: jan. 2018. (23 min.).

58 BERNARDO, Teresinha. Memória em branco e negro: olhares sobre São Paulo, p. 54.

${ }^{59}$ NEPOMUCENO, Bebel. Mulheres Negras - "Protagonismo Ignorado", p. 96.
} 
No contexto da população negra e, principalmente da mulher negra, temos outro fator agravante dessa situação, a questão da escolaridade. A educação é vista pela maioria como uma forma de ascender socialmente e ter melhores condições de vida. A mulher branca conseguiu adentrar mais os níveis superiores ao longo dos anos, segundo os censos, diminuindo a distância dos homens brancos, mas a população negra não atingiu da mesma forma, muito menos a mulher negra. Portanto, esta última tem menos possibilidades em termos proporcionais em relação aos grupos sociais. Nepomuceno atesta que:

Porém, desde muito cedo, a população negra, e a mulher negra em particular, teve maiores dificuldades em integrar o quadro educacional (os reflexos disso podem ser sentidos ainda nos dias atuais. (...) No pós-abolição, por conta do racismo existente na sociedade, essa população encontrou dificuldade de obter um lugar nos bancos escolares da rede pública ${ }^{60}$.

$\mathrm{Na}$ comunidade as mulheres apontavam para as grandes dificuldades encontradas por eles para estudar, pois além de cuidar da casa, dos filhos, do roçado e muitas vezes da lida no engenho com os homens ou procurar empregos como domésticas para completar a renda da família, não tinham condições de frequentar uma escola. As moradoras mais velhas nos dizem que não podiam estudar, bem como suas mães e avós, pois com condições precárias não tinham como frequentar a escola, tendo que trabalhar pra ajudar em casa desde muito cedo. Portanto, a necessidade de trabalhar e a falta de renda sempre manteve as mulheres negras afastadas do universo escolar, "dando-se o mesmo com seus filhos e filhas, ingressados precocemente no mercado de trabalho para ajudar na renda familiar, atuando em trabalhos de baixa remuneração"61.

Atualmente, ao conversamos com algumas moradoras, descobrimos que algumas haviam terminado o ensino médio, outra havia feito um curso sobre plantas medicinais para aprofundar seus conhecimentos, tendo em vista que já se utilizava de ervas para tratamentos, outras estão investindo em hortas para comercialização. E assim estão cada vez mais alcançando voos em busca de melhores condições de vida e independência, mas salientam que foi após o reconhecimento como quilombolas que tiveram mais oportunidades de vida.

\footnotetext{
${ }^{60}$ NEPOMUCENO, Bebel. Mulheres Negras - "Protagonismo Ignorado", p. 389.

${ }^{61}$ NEPOMUCENO, Bebel. Mulheres Negras - "Protagonismo Ignorado", p. 394.
} 


\section{Considerações Finais}

Através dos censos e de uma historiografia local, mapeamos a população feminina, no município de Areia, ao longo dos anos. Destacando que, mesmo no pósabolição, a sua situação não mudara significativamente. Constatamos que a mulher negra, por sua vez sendo mulher e negra, se manteve desempenhando os papéis que lhe foram relegados desde a escravidão, ocupando espaços domésticos e trabalhos rurais. Na comunidade, por exemplo, apesar de ocuparem esses espaços e na maioria das vezes exercendo funções tidas como do "universo masculino", não chegavam a receber nenhum valor em troca de seus serviços, além das dificuldades de ascender socialmente.

Observamos que durante várias décadas a maior parte da população estava concentrada na zona rural, principalmente a negra. Além disso, analisamos o contexto da chegada de Dona Mariquinha, que coincide com a chegada do primeiro morador, que também viveu na condição de moradora no Engenho Bonfim, o que enfatiza a figura feminina na constituição do grupo.

Por fim pudemos constatar que a situação era precária, trabalhavam na agricultura, no "eito", no ambiente doméstico, não tendo uma educação escolar, vivendo sempre

relações assimétricas advindas do sistema de morador. Restava apenas às famílias trabalharem muitas vezes em condições desumanas para se sustentar. São reflexos de uma sociedade excludente, que não proporcionou oportunidades para que as mulheres negras tivessem melhores condições de vida. Porém, não podemos deixar de ressaltar que essas mulheres lutaram e lutam por melhores condições de vida.

Data de submissão: 28/10/2019

Data de aceite: 05/04/2020 


\section{Fontes}

\section{Fontes Orais}

Josefa Mariano Faustino dos Santos, entrevista concedida à autora em: mar. 2017. (1h 15 min.).

Severina Gomes de Sousa, entrevista concedida à autora em: jan. 2018. (23 min.).

\section{Fontes Impressas}

BRASIL. Relatório Antropológico de Reconhecimento e Delimitação do Território da Comunidade Negra Senhor do Bonfim. Instituto Nacional de Colonização e Reforma Agrária - INCRA, Superintendência Regional - Paraíba, n. 18, João Pessoa, 2007.

\section{Fontes Digitais}

ASSOCIAÇÃO BRASILEIRA DE ANTROPOLOGIA - ABA. Documento do Grupo de Trabalho sobre Comunidades Negras Rurais. Rio de Janeiro: 1994. Disponível em: <www.abant.org.br/?code=2.39 >. Acesso em: 20 set. 2017.

INSTITUTO BRASILEIRO DE GEOGRAFIA E ESTATÍSTICA - IBGE. Censo de 1872. Arquivo Digital da Biblioteca do Instituto Histórico e Geográfico Brasileiro (ADBIHGB). Disponível em:

<http://biblioteca.ibge.gov.br/visualizacao/livros/liv25477_v5_pb.pdf> $>$. Acesso em: 05 set. 2016.

INSTITUTO BRASILEIRO DE GEOGRAFIA E ESTATÍSTICA - IBGE. Censo de 1890. 1905. Arquivo Digital da Biblioteca do Instituto Histórico e Geográfico Brasileiro (ADBIHGB). Disponível em:

$<$ http://biblioteca.ibge.gov.br/index.php/biblioteca-catalogo?view=detalhes\&id=51 $>$.

Acesso em: 05 set. 2016.

INSTITUTO BRASILEIRO DE GEOGRAFIA E ESTATÍSTICA - IBGE. Censo de 1900. 1907. Arquivo Digital da Biblioteca do Instituto Histórico e Geográfico Brasileiro (ADBIHGB). Disponível em:

<http://www2.senado.leg.br/bdsf/item/id/222260 >. Acesso em: 14 set. 2016.

INSTITUTO BRASILEIRO DE GEOGRAFIA E ESTATÍSTICA - IBGE. Censo de 1920. Arquivo Digital do Ministério da Agricultura (ADMA). Disponível em: $<$ https://archive.org/search.php?query=creator\%3A"BRASIL\%2C+Ministerio+da+Agri cultura $\% 2 \mathrm{C}+$ Industria+e+Commercio.+Directoria+Geral+de+Estatística $>$. Acesso em: 20 out. 2016 


\section{Referências Bibliográficas}

BERNARDO, Teresinha. Memória em branco e negro: olhares sobre São Paulo. São Paulo: EDUC; Editora UNESP, 1998.

COSTA, Emília Viotti da. A abolição. 9. ed. São Paulo: Editora UNESP, 2010.

CRENSHAW, Kimberlé. A interseccionalidade na discriminação de raça e gênero. Brasília: Unifem, 2004. Disponível em: <http://www.acaoeducativa.org.br/fdh/wpcontent/uploads/2012/09/Kimberle-Crenshaw.pdf>. Acesso em: 20 abr. 2018.

DAVIS, Angela. Mulheres, raça e classe. São Paulo: Boitempo, 2016.

DIAS, Maria Odila Leite da Silva. Cotidiano e Poder em São Paulo no séc. XIX. São Paulo: Brasiliense, 1984.

GIACOMINI, Sônia Maria. Mulher e Escrava: uma introdução histórica ao estudo da mulher negra no Brasil. Petrópolis: Vozes, 1985.

GONZALEZ, Lélia. A mulher negra na sociedade brasileira. In: LUZ, Madel Therezinha (Org.). O Lugar da Mulher: estudos sobre a Condição Feminina na sociedade atual. Rio de Janeiro: Edições Graal, 1982.

MOTT, Maria Lucia de Barros. Submissão e Resistência: a mulher na luta contra a escravidão. São Paulo: Contexto, 1998.

NASCIMENTO, Beatriz. A mulher negra na sociedade brasileira. In: RATTS, Alex. Eu sou Atlântica: sobre a trajetória de Beatriz Nascimento. São Paulo: Imprensa Oficial do Estado de São Paulo: Instituto Kuanza, 2007.

NEPOMUCENO, Bebel. Mulheres Negras - "Protagonismo Ignorado". In: PINSKY, Carla Bassenezi; PEDRO, Joana Maria (Org.). Nova História das Mulheres. São Paulo: Editora Contexto, 2013.

PERROT, Michelle. Minha História das Mulheres. São Paulo: Editora Contexto, 2015.

POLLAK, Michael. Memória e Identidade Social. Revista Estudos Históricos. Rio de Janeiro, v. 05, n. 20, 1992.

PORTELLI, Alessandro. História oral como arte da escuta. São Paulo: Letra e Voz, 2016.

RAGO, Margareth Luzia. As mulheres na historiografia brasileira. In: Zélia Lopes Silva (Org.). Cultura Histórica em Debate. São Paulo: UNESP, 1995.

ROCHA, Solange Pereira da. Na Trilha do Feminino: condições de vida das mulheres escravizadas na província da Paraíba, 1828-1888. 2001. Dissertação (Mestrado em História) - Centro de Filosofia e Ciências Humanas, Universidade Federal de Pernambuco, Recife-PE. 
ROCHA, Solange Pereira da. Antigas personagens, novas histórias: memórias e histórias de mulheres escravizadas na Paraíba oitocentista. Brasília: Secretaria Especial de Políticas para as Mulheres da Presidência da República, 2006.

ROCHA, Solange Pereira da. Gente Negra na Paraíba Oitocentista: População, Família e Parentesco Espiritual. 2007. Tese (Doutorado em História) - Centro de Filosofia e Ciências Humanas, Universidade Federal de Pernambuco.

SANTOS, Geilza da Silva. Mulheres quilombolas: Território, gênero e identidade na Comunidade Negra Senhor do Bonfim, Areia/PB (2005-2018). 2018. Dissertação (Mestrado em História) - Centro de Ciências Humanas, Letras e Artes, Universidade Federal da Paraíba, João Pessoa-PB.

SANTOS, Thereza. Malunga Thereza Santos: a história de vida de uma guerreira. São Carlos: EDUFSCAR, 2008.

SCOTT, Joan. História das Mulheres. In: BURKE, Peter (Org.). A Escrita da História: novas perspectivas. São Paulo: UNESP, 1992.

SOIHET, Raquel; PEDRO, Joana Maria. A emergência da pesquisa da História das Mulheres e das Relações de Gênero. Revista Brasileira de História. São Paulo, v. 27, n. 54, 2007.

SOUTO, Pedro Nicácio. Areia: uma "aldeia" negra paraibana de fins do século XIX e as primeiras décadas do século XX. 2015. Dissertação (Mestrado em História) - Centro de Humanidades, Universidade Federal de Campina Grande, Campina Grande-PB.

SOUZA, Flavia Fernandes de. Escravas do lar: as mulheres negras e o trabalho doméstico na Corte Imperial. In: XAVIER, Giovana; FARIAS, Juliana Barreto; GOMES, Flávio (Orgs.). Mulheres negras no Brasil escravista e do pós-emancipação. São Paulo: Selo Negro Edições, 2012.

XAVIER, Giovana; FARIAS, Juliana Barreto; GOMES, Flávio (Orgs.). Mulheres negras no Brasil escravista e do pós-emancipação. São Paulo: Selo Negro Edições, 2012. 